\title{
Flow Injection Spectrophotometric Analysis of Human Salivary $\alpha$-Amylase Activity Using an Enzyme Degradation of Starch-Iodine Complexes in Flow Channel and Its Application to Human Stress Testing
}

\author{
Takao Ohtomo, ${ }^{a}$ Shukuro Igarashi, ${ }^{b}$ and Yoshitaka Takagai*,a \\ ${ }^{a}$ Faculty of Symbiotic Systems Science, Fukushima University; 1 Kanayagawa, Fukushima 960-1296, Japan: and \\ ${ }^{b}$ Department of Biomolecular Functional Engineering, Collage of Engineering, Ibaraki University; 4-12-1 \\ Nakanarusawa, Hitachi, Ibaraki 316-8511, Japan. \\ Received March 14, 2013; accepted August 12, 2013
}

\begin{abstract}
Flow injection spectrophotometric analysis (FIA) of human salivary $\alpha$-amylase was developed using an enzyme degradation reaction of starch-iodine complexes. In this proposed method, the salivary $\alpha$-amylase, known as a human stress indicator, is directly and rapidly determined without any pretreatment. In this study, the optimum starch-iodine complexes (i.e., optimum molecular weight and amylase-amylopectin compounding ratio) were selected, and their rapid degradation in the flow channel was investigated to determine salivary amylase in the FIA system. The determination range of $\alpha$-amylase was obtained from 0.25 to 5.0 kilo Novo unit per milliliter $(\mathrm{KNU} / \mathrm{mL})$, and these concentrations were equivalent to the real concentration of amylase in human saliva. The quantitative values obtained by this method were found to be highly reproducible with $1.6 \%(n=25)$ of the relative standard deviation for $1.0 \mathrm{KNU} / \mathrm{mL}$. The detection limit $(3 \sigma)$ was 60 $\mathrm{NU} / \mathrm{mL}$. In addition, the method requires small volume of a sample $(20 \mu \mathrm{L})$, and 30 samples was sequentially measured within one hour. Real human saliva collected before and after exercise was utilized to demonstrate the feasibility of human stress test and analytical performance of this approach.
\end{abstract}

Key words $\alpha$-amylase activity; flow injection analysis; starch-iodine reaction; saliva; human stress test

Stress negatively impacts human health, both physically and psychologically; therefore, there is much interest in topics such as stress prevention, release, measurement, and medical treatment. To reduce human stress, an effective method for diagnosing (or evaluating) the degree of stress is required. To date, a typical diagnosis of stress has been performed by medical inquiries and questionnaire surveys, where the diagnosis depends on the doctor's individual experience and/or the patient's sensation. Thus, biochemical support has been required in stress diagnosis. From the viewpoint of stress evaluation, a quantitative method using a chemical indicator is being developed. Cortisol and norepinephrine have been used as stress indicators in blood to quantify the degree of imposed stress on the body, with the disadvantages of collecting blood samples. ${ }^{1,2)}$ Otherwise, chromogranins ${ }^{3,4)}$ and immunoglobulin A have been used as stress indicators in saliva and are typically measured by enzyme-linked immunosorbent assay (ELISA). In contrast, $\alpha$-amylase indicates the index of the activity of the sympathetic nerve, and is a useful stress indicator compared to cortisol ${ }^{1,2)}$ because the samples can be easily collected with sufficient volumes and indicator concentrations for detection by analytical instruments. A specific feature of salivary amylase is that the amylase activity increases in unwanted affairs such as unpleasant stimuli. In contrast, the opposite stimuli (i.e., pleasant, wanted and hopeful affairs; no burden in one's mind or physical) decrease the amylase activity. These features of amylase in saliva have been applied to the discrimination method for human stress. ${ }^{5,6}$ In addition, the salivary amylase activity increases under not only physical stress $^{7)}$ but also psychosocial stress. ${ }^{8)}$ Stress diagnosis using salivary amylase as an indicator was conducted by spectrophotometry with ELISA ${ }^{9)}$ and a chemosensor (saliva amylase monitor). ${ }^{10,11)}$

The authors declare no conflict of interest
Though a plethora of reports have concerned the quantitative methods for $\alpha$-amylase, ${ }^{12-16)}$ the determination ranges of these methods are outside the concentration of salivary amylase. Hence, the direct analysis of saliva is difficult. Particularly, it is not possible to sequentially analyze many samples in a short time. Otherwise, flow injection analysis is a high-performance analytical technique that measures several samples in a short time. The difficulty in flow injection analysis using enzyme reactions is to secure the required reaction time of the enzyme reaction in the fast flow of the flow injection system. In this study, the rapid decomposition of several iodine-starch complexes with amylase was investigated with the flow injection system and applied to the sequential determination of salivary amylase using flow injection spectrophotometric analysis (FIA). In addition, samples of human saliva collected before and after exercise were utilized to demonstrate the feasibility of the human stress test and the analytical performance of this system.

\section{MATERIALS AND METHODS}

Materials One hundred twenty kilo Novo unit per gram (KNU/g) of certified $\alpha$-amylase solutions was obtained from MP Products (U.S.A.) via Wako Pure Chemical Industries, Ltd. (Osaka, Japan), where $1 \mathrm{KNU}$ is the amount of enzyme that breaks down $5.26 \mathrm{~g}$ of starch per hour using Novo Nordisk's standard method for the determination of alpha amylase. Diluted working solutions were obtained by appropriate dilution of these stock solutions using distilled water. Amyloses (molecular weight $(\mathrm{MW})=2800$ and 15000) were obtained from Tokyo Chemical Industry (Tokyo, Japan). Potassium iodide and iodine were obtained from Nacalai Tesque, Inc. (Kyoto, Japan). Various starches were obtained from Nihon Shokuhin Kako Co., Ltd. (Tokyo, Japan) as follows: Nisshoku waxy starch $\mathrm{Y}^{\circledR}$, Nisshoku corn starch $\mathrm{Y}^{\circledR}$, and high amylose 
$\operatorname{starch}^{\circledR}$ were employed as $100 \%$ amylopectin, $75 \%$ amylopectin (25\% amylose), and 30\% amylopectin ( $70 \%$ amylose), respectively. All other reagents were of analytical grade.

A $1.0 \times 10^{4} \mathrm{ppm}$ iodine stock solution was prepared as follows: $1 \mathrm{~g}$ of iodine was dissolved in $10 \mathrm{~mL}$ of a $4.0 \times 10^{5} \mathrm{ppm}$ potassium iodide solution (as a solubilizer for iodine), and then distilled water was added to the solution to adjust to $100 \mathrm{~mL}$. Dilute working solutions were obtained by diluting these stock solutions using distilled water. Concentrated solutions of starch compounds were prepared using water as a solvent with stirring while heating. The more dilute working solutions were obtained by diluting these stock solutions using water (without heating). A fresh starch stock solution was prepared every day. The mixture of starch and iodine-potassium iodide was used as the working solution, and the solution was also used as a career solution for FIA (typical components were $[\mathrm{starch}]_{\mathrm{T}}=100 \mathrm{ppm}$ and $[\text { iodine }]_{\mathrm{T}}=20 \mathrm{ppm}$ ).

Apparatus A JASCO V-560 spectrophotometer (JASCO Inc., Tokyo, Japan) with a JASCO EHC-477 single position Peltier-thermostated cell holder was used, along with a quartz cell having an optical path length of $1 \mathrm{~cm}$. The flow injection analysis system was used in the combination of components as follows: A Hitachi L-2455 diode array detector (DAD, Hitachi High-Technologies Co., Ltd., Tokyo, Japan) was used, and the measurement wavelength for the quantification was set to measure absorbance at $620 \mathrm{~nm}$. A Hitachi L-2130 double plunger-type pump was employed at the isocratic flow rate of $1.6 \mathrm{~mL} / \mathrm{min}$. A Hitachi L-2350 column oven was used as a reactive oven and was set at $37^{\circ} \mathrm{C}$. A Rheodyne ${ }^{\circledR}$ switching low-pressure injector valve (IDEX, Rohnert Park, CA, U.S.A.) with a $20 \mu \mathrm{L}$ metal loop was used for manual injection. Teflon tubing (o.d. $1.58 \mathrm{~mm} /$ i.d. $1.0 \mathrm{~mm}$ ) (GL Sciences, Tokyo, Japan) was used as the flow tube for the flow injection system. The reaction coil (RC) was prepared by cutting a 12-m-long Teflon tubing (volume: $8.4 \mathrm{~mL}$ ), and it was placed into the reactor (at $\left.37^{\circ} \mathrm{C}\right)$.

Subjects A total of twenty-three undergraduate students, 17 men and 6 women, ranged in age from 19 to 22 years (mean age: man, 19.0 years; woman, 18.8 years), participated in the present study. The purpose of this study was fully explained to all the subjects, and their consent to participate and permission to use the data in this study were obtained. The ethical committee of Fukushima University approved the study protocol (No. 25-08).

Measurement of the Initial Rate in the $\alpha$-AmylaseCatalyzed Reactions Before constructing the flow injection system, the fundamental spectrophotometric data such as the initial rate of the $\alpha$-amylase enzyme reaction was obtained using the spectrophotometer. Typical experiments were conducted with $400 \mu \mathrm{L}$ of $200-2000 \mathrm{ppm}$ starches as a substrate, $200 \mu \mathrm{L}$ of a $200 \mathrm{ppm}$ iodine solution (concentration was defined as the iodine $\left(\mathrm{I}_{2}\right)$ in spite of iodine-potassium iodide), and $1000 \mu \mathrm{L}$ of $\mathrm{pH} 4$ citric acid-phosphoric acid buffer $(0.08 \mathrm{~mol} / \mathrm{L})$ was added into the $1 \mathrm{~cm}$ quartz cuvette. After the cuvette was placed in the appropriate position in spectrophotometer, $400 \mu \mathrm{L}$ of $0.5 \mathrm{KNU} / \mathrm{mL} \alpha$-amylase was added to the cuvette. The enzyme reaction started at the moment of the $\alpha$-amylase addition. The absorption spectra were measured every $2 \mathrm{~min}$ over a $10 \mathrm{~min}$ reaction time.

The Flow Injection System and Determination of $\boldsymbol{\alpha}$-Amylase Activity The solution of the starch-iodine complex $\left([\mathrm{starch}]_{\mathrm{T}}=100 \mathrm{ppm}\right.$ and $\left.[\text { iodine }]_{\mathrm{T}}=20 \mathrm{ppm}\right)$ as a carrier was set at $1.6 \mathrm{~mL} / \mathrm{min}$, and $20 \mu \mathrm{L}$ of a sample solution was injected through the injector into the flow system (see Fig. S1 in Supplemental Information section). The measurement time (from sample injection to peak detection) was $4 \mathrm{~min}$. The detected flow signals represented the absorbance of starch-iodine (milli absorbance units (mAU) at $620 \mathrm{~nm}$ ), thereby the net absorbance $(\triangle \mathrm{Abs}, \mathrm{mAU})$, which was caused by the discoloration of enzyme degradation, was calculated from the difference between the absorbance of a blank signal and sample signal, i.e., absorbance (blank)-absorbance (sample). The calibration curves were prepared using $\Delta \mathrm{Abs} v$ s. $\alpha$-amylase activities.

\section{RESULTS AND DISCUSSION}

Spectrophotometric Properties of Starch-Iodine Complexes Initial screening studies were conducted to determine the type of iodine-amylose complex to be used in the spectrophotometric response of the amylase enzyme degradation. The absorption spectra of the starch-iodine complexes are shown in Fig. 1. Figure 1(a) shows the absorption spectra of amylose-iodine complexes in different molecular weight amyloses (MW 2800 and 15000 for spectra A and B, respectively). The amyloses with molecular weights of 2800 (spectrum A) and
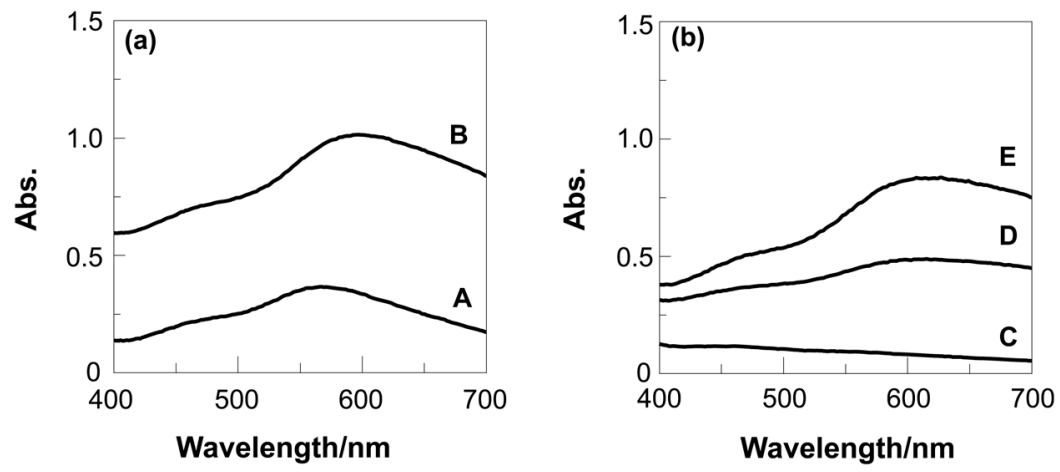

Fig. 1. Absorption Spectra of Amylose-Iodine Complexes (a) and Starch-Iodine Complexes (b)

Spectrum A, amylose (MW 2800)-iodine complex, spectrum B, amylose (MW 15000)-iodine complex, spectrum C, 100\% amylopectin (waxy starch)-iodine complex, spectrum D, 70\% amylose-30\% amylopectin (high amylose starch)-iodine complex, and spectrum E, $25 \%$ amylose-75\% amylopectin (corn starch)-iodine complex. The experimental conditions were [iodine $]_{\mathrm{T}}=20 \mathrm{ppm}$, [amylose or starch $]_{\mathrm{T}}=200 \mathrm{ppm}, \mathrm{pH}=4$, and temperature at $37^{\circ} \mathrm{C}$. The maximum wavelengths $\left(\lambda_{\text {max }}\right)$ of the spectra were 570, $600,550,620$, and $620 \mathrm{~nm}$ for the order of the spectrum A-E, respectively. 
15000 (spectrum B) have maximum absorption wavelengths $\left(\lambda_{\max }\right)$ of 570 and $600 \mathrm{~nm}$, and molar absorbance coefficients ( $\varepsilon$ ) of $\varepsilon_{570}=5100$ and $\varepsilon_{600}=76000 \mathrm{~L} / \mathrm{mol} \mathrm{cm}$, respectively. The colors of the solutions were observed to be red-violet and blue-violet. The $\varepsilon$ of the amylose-iodine complex remarkably increased with the molecular weight of the amylose, and the $\lambda_{\max }$ slightly shifted to longer wavelengths. In addition, Fig. 1(b) shows the absorption spectra of some starch-iodine complexes in a different amylose/amylopectin (Am/Ap) ratio in starch. The $\lambda_{\max }$ were 550,620 , and $620 \mathrm{~nm}$ for $100 \%$ amylopectin, 75\% amylopectin-25\% amylose, and 30\% amylopectin-70\% amylose, respectively. The color changes of the solutions were observed from red-violet to blue-violet according to the increase in Am/Ap ratio in starch, and the $\lambda_{\text {max }}$ slightly shifted to longer wavelengths.

Enzyme Degradation of Starch-Iodine Complexes in Flow Tubing When $\alpha$-amylase was added to a solution of a starch-iodine complex, the absorption of the complex was decreased (see Fig. S2 in Supplemental Information section). The starch-iodine complex was decomposed by the addition of $\alpha$-amylase, and a decrease in the absorbance (at $\lambda=620 \mathrm{~nm}$ ) was confirmed. As a result of screening, the color of the iodine-amylose complex (MW 2800) was sharply changed by the concentration of human salivary amylase. However, the molecular weight certified amylose (purified amylose) is very expensive and hence is not suitable for conducting sequential quantifications with respect to cost effectiveness. In contrast, plantal starches such as corn starch and waxy starch are commercially available and very reasonably priced compared with the certified materials. The corn starch (i.e., 75\% amylopectin-25\% amylose) served as a substitutable substrate for color degradation pigment among the substrate screening of plantal starches (100\% amylopectin for waxy, 75\% amylopectin- $25 \%$ amylose for corn, and 30\% amylopectin-70\% amylose for an artificial blend). The complex of the corn starch-iodine reacted with the concentration of human salivary amylase and showed good color degradation. The time-dependent response (via color degradation of an iodine-corn starch complex) of the relative amylase concentration is shown in Fig. 2. Depending upon the concentration of human salivary amylase, the color degradation of the starch-iodine complex was obviously observed at $240 \mathrm{~s}$. To gain sufficient reaction time (between the substrate in the carrier and the enzyme in the sample) in

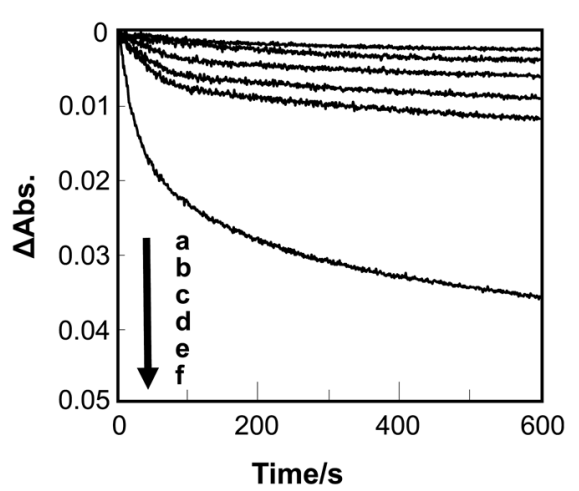

Fig. 2. $\triangle$ Absorbance vs. Time Curves with Different Concentrations of [25\% Amylase-75\% Amylopectin (Corn Starch) $]_{\mathrm{T}}$ : (a) 40, (b) 80, (c) 120, (d) 160 , (e) 200 , and (f) $400 \mathrm{ppm}$

The experimental conditions were $[\text { iodine }]_{\mathrm{T}}=20 \mathrm{ppm},[\alpha \text {-amylase }]_{\mathrm{T}}=0.02 \mathrm{KNU}$ / $\mathrm{mL}, \mathrm{pH}=4$, and temperature at $37^{\circ} \mathrm{C}$. The measurement wavelength was $620 \mathrm{~nm}$. the flow tubing of the flow injection system, the sample flowed $(1.6 \mathrm{~mL} / \mathrm{min})$ and spent $240 \mathrm{~s}$ in the $12 \mathrm{~m} \mathrm{RC}$ under $37^{\circ} \mathrm{C}$; the detection time was $240 \mathrm{~s}$ from the injection time $(0 \mathrm{~s})$. Changing the flow rate and $\mathrm{RC}$ length impacted the flow chart and sensitivities of amylase. i.e., Decrease in peak intensities (absorbance) was observed in the flow chart, because of the dilution and diffusion of the sample to carrier solution in flow tubing.

Enzyme Properties of Amylase, the Affinity with the Starch-Iodine Complex, and Optimization for Flow Injection Analysis The relationship between reaction velocities and the concentration of the substrate $\left([\mathrm{starch}]_{\mathrm{T}}=40-400 \mathrm{ppm}\right)$ was measured (see Fig. S3 in Supplemental Information section), and then the Lineweaver-Burk plotting (1/Vi vs. 1/ [S]) was obtained (see Fig. S4 in Supplemental Information section). The Michaelis constant $\left(K_{\mathrm{m}}\right)$ of the substrate and maximum reaction rate $\left(V_{\max }\right)$ are shown in Table 1 . From the results, the amylase's affinity for the substrate and their $V_{\max }$ both follow the order: iodine-amylose (MW 2800)>iodineamylose (MW 15000)>iodine-corn starch (75\% amylopectin-25\% amylose) $>$ iodine-high amylose starch $(30 \%$ amylopectin-70\% amylose) $>$ iodine-waxy starch (100\% amylopectin). In the case of an indirect quantitative analysis in flow injection, it is very important to obtain a recognizable difference in the peak intensities between the blank signal and the signal of the analytical target. In this study, the condition of $1.0 \mathrm{KNU} / \mathrm{mL} \alpha$-amylase was employed as the pseudo condition of human saliva to optimize the flow injection system for amylase quantification. The optimum final concentrations of corn starch and iodine-potassium iodide were found to be $100 \mathrm{ppm}$ and $20 \mathrm{ppm}$, respectively. Optimum $\mathrm{pH}$ conditions were investigated between 3 and 7, and 4 was observed to be optimum. For pH 5 and above, the absorbance of starch-iodine complex decreased owing to hydrolysis. ${ }^{14)}$ In addition, temperature impacts the helical structure of iodine-starch complex ${ }^{17)}$ so that the temperature was fixed at $37^{\circ} \mathrm{C}$. For instance, the peak intensities (or absorbance) of the complex were decreased with temperature in order to dissociate between iodine and starch (broken helix structure).

Analytical Merits of the Proposed Method The calibration curve of the absorbance as a function of $\alpha$-amylase activity was measured (see Fig. S5 in Supplemental Information section). A satisfactory linearity was obtained in the range of $0.25-5.0 \mathrm{KNU} / \mathrm{mL}$ in $\alpha$-amylase activity. The best fit calibration equation was determined to be

$$
\text { net } \mathrm{Abs}_{620 \mathrm{~nm}}=82.9[\alpha \text {-amylase activity }]_{\mathrm{T}}+0.15
$$

where net $\mathrm{Abs}_{620 \mathrm{~nm}}$ represents the difference of the absor-

Table 1. Michaelis Constant $\left(K_{\mathrm{m}}\right)$ and Maximum Reaction Rate $\left(V_{\max }\right)$ of Substrate

\begin{tabular}{lcc}
\hline \hline \multicolumn{1}{c}{ Substrate } & $K_{\mathrm{m}}(\mathrm{g} / \mathrm{L})$ & $V_{\max }(\Delta A / \min )$ \\
\hline Amylose (MW 2800) & 0.307 & 0.128 \\
Amylose (MW 15000) & 0.332 & 0.123 \\
Corn starch & 0.388 & 0.086 \\
High amylose starch & 0.447 & 0.061 \\
Waxy starch & 0.699 & 0.027 \\
\hline
\end{tabular}

The experimental conditions were $[\text { substrate }]_{\mathrm{T}}=40-400 \mathrm{ppm},[\text { iodine }]_{\mathrm{T}}=20 \mathrm{ppm}$, $[\alpha \text {-amylase }]_{\mathrm{T}}=0.02 \mathrm{KNU} / \mathrm{mL}, \mathrm{pH}=4$, and temperature at $37^{\circ} \mathrm{C}$. The detected wavelength was individual $\lambda_{\max }$ of starch-iodine complex (see the caption of Fig. 1). 
bance at $620 \mathrm{~nm}$ between the target and blank signals, and $[\alpha \text {-amylase activity }]_{\mathrm{T}}$ represents the final concentration of $\alpha$-amylase activity (in $\mathrm{KNU} / \mathrm{mL}$ ). The correlation coefficient was 0.993 and the relative standard deviation was $1.6 \%$ $(n=25)$ at $1.0 \mathrm{KNU} / \mathrm{mL}$ of $\alpha$-amylase activity. The detection limit (based on $3 \sigma$ ) was $60.0 \mathrm{NU} / \mathrm{mL}$. An advantage of the proposed method is that it can measure human saliva without any pretreatment, even without dilution. The processing of thirty samples per hour was achieved with this technique. This methodology focuses on the sequential measurement of real human saliva samples in short time. Previous techniques for such analyses required sample pretreatment and direct analysis of saliva was not possible. ${ }^{13)}$

Practical Application for Determination of Salivary $\boldsymbol{\alpha}$-Amylase The proposed method was applied to some real saliva samples to demonstrate the applicability of the technique. The saliva samples were obtained from 23 undergraduate students who are not professional athlete or special trained game player, and collected a $30 \mathrm{~min}$ before exercise (rest time), a moment before exercise and after exercise ( $2 \mathrm{~h}$ later). The measured mean values before and after exercise, were 3.10士 0.06 and $3.84 \pm 0.07 \mathrm{KNU} / \mathrm{mL}$, respectively. $\alpha$-Amylase activity values before and after exercise are shown in Table 2 . Flow signals of the FIA; (a) standard materials of $\alpha$-amylase and (b) human saliva are shown in Fig. 3. From these results, $\alpha$-amylase activity increased after the exercise. A previous paper reported $\alpha$-amylase activity as an indicator of fatigue that increased with exercise. ${ }^{7,18)}$ In that previous report, ${ }^{7)}$ for instance, the samples were obtained from eight well-trained male games players from age $25 \pm 1$ years-old, and collected before and after exercise (cycle exercise task in $5 \mathrm{~min}$ ). Saliva $\alpha$-amylase activity was measured using an ELISA kit in a microtitration plate. The measured mean values before and after exercise were $0.19 \pm 0.06$ and $1.09 \pm 0.38 \mathrm{KNU} / \mathrm{mL}$, respectively, thus $\alpha$-amylase activity increased after the exercise.

The tendency between this method and published literature regarding the behavior that body stress (physical exercise) impacted to the concentration of salivary amylase and the de-
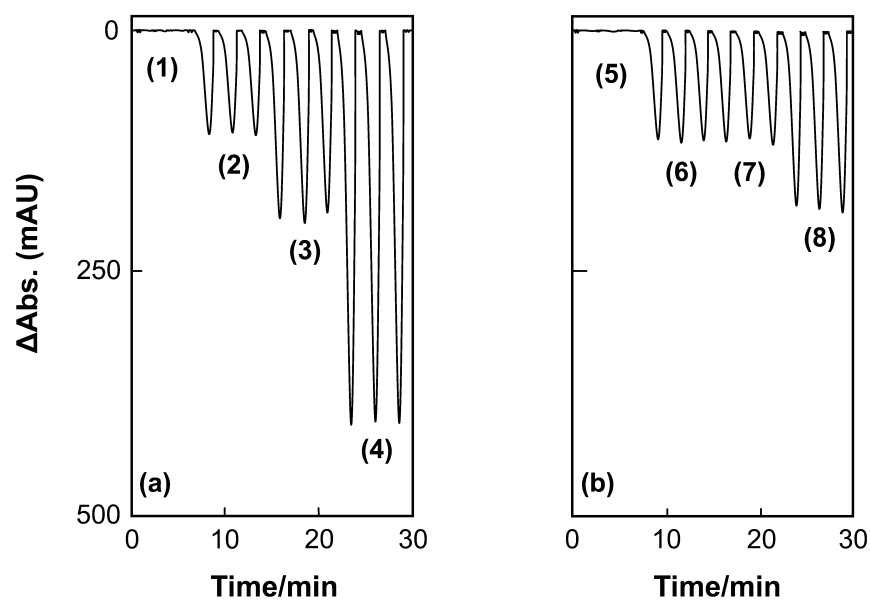

Fig. 3. Flow Signals of the FIA; (a) Standard Materials of $\alpha$-Amylase and (b) Human Saliva

The experimental conditions were $[25 \%$ amylose- $75 \%$ amylopectin (corn starch) $]_{\mathrm{T}}=100 \mathrm{ppm},[\text { iodine }]_{\mathrm{T}}=20 \mathrm{ppm}, \mathrm{pH}=4$, and temperature at $37^{\circ} \mathrm{C}$. Left side window(a): the $\alpha$-amylase concentration of signals obtains were: (1) 0.0 , (2) 1.0 , (3) 2.5 , (4) $5.0 \mathrm{KNU} / \mathrm{mL}$. Right side window (b): The human saliva of signals obtains were (5) blank, (6) saliva in term of rest time (30 min before exercise), (7) a saliva just before exercise and (8) a saliva after $2 \mathrm{~h}$ exercise. The data was corresponded with the data of subject $\mathrm{C}$ in Table 2. $\triangle$ Absorbance (mAU at $620 \mathrm{~nm}$ detection $)=$ absorbance $($ blank $)-$ absorbance $($ sample $)$

Table 2. $\alpha$-Amylase Activity Values before and after Exercise (Mean \pm S.D., $n=3$ )

\begin{tabular}{|c|c|c|c|}
\hline Subject & $\operatorname{Rest}^{a)}(\mathrm{KNU} / \mathrm{mL})$ & Pre-exercise ${ }^{b)}(\mathrm{KNU} / \mathrm{mL})$ & Post-exercise $^{c)}(\mathrm{KNU} / \mathrm{mL})$ \\
\hline A & $3.41 \pm 0.05$ & $3.88 \pm 0.06$ & $4.32 \pm 0.07$ \\
\hline B & $3.66 \pm 0.06$ & $4.18 \pm 0.07$ & $4.70 \pm 0.10$ \\
\hline $\mathrm{C}$ & $1.13 \pm 0.02$ & $1.14 \pm 0.03$ & $1.83 \pm 0.04$ \\
\hline $\mathrm{D}$ & $2.66 \pm 0.06$ & $3.00 \pm 0.07$ & $3.84 \pm 0.06$ \\
\hline $\mathrm{E}$ & $4.17 \pm 0.08$ & $4.46 \pm 0.07$ & $4.78 \pm 0.07$ \\
\hline $\mathrm{F}$ & $3.13 \pm 0.05$ & $3.41 \pm 0.07$ & $4.29 \pm 0.07$ \\
\hline G & $3.51 \pm 0.05$ & $3.86 \pm 0.08$ & $4.51 \pm 0.07$ \\
\hline $\mathrm{H}$ & $1.64 \pm 0.04$ & $1.74 \pm 0.04$ & $2.68 \pm 0.06$ \\
\hline I & $2.07 \pm 0.05$ & $3.21 \pm 0.06$ & $4.22 \pm 0.07$ \\
\hline $\mathrm{J}$ & $3.50 \pm 0.06$ & $4.05 \pm 0.07$ & $4.49 \pm 0.07$ \\
\hline $\mathrm{K}$ & $2.86 \pm 0.05$ & $3.31 \pm 0.06$ & $4.19 \pm 0.08$ \\
\hline $\mathrm{L}$ & $3.08 \pm 0.05$ & $3.32 \pm 0.06$ & $3.78 \pm 0.06$ \\
\hline $\mathrm{N}$ & $3.20 \pm 0.05$ & $3.53 \pm 0.07$ & $3.93 \pm 0.06$ \\
\hline M & $3.11 \pm 0.05$ & $3.56 \pm 0.06$ & $4.23 \pm 0.06$ \\
\hline $\mathrm{O}$ & $3.11 \pm 0.05$ & $3.85 \pm 0.07$ & $4.88 \pm 0.07$ \\
\hline $\mathrm{P}$ & $2.52 \pm 0.04$ & $3.53 \pm 0.07$ & $4.98 \pm 0.09$ \\
\hline Q & $2.00 \pm 0.04$ & $2.18 \pm 0.04$ & $2.79 \pm 0.06$ \\
\hline $\mathrm{R}$ & $2.33 \pm 0.04$ & $2.96 \pm 0.06$ & $4.21 \pm 0.07$ \\
\hline $\mathrm{S}$ & $2.51 \pm 0.06$ & $2.72 \pm 0.04$ & $3.34 \pm 0.07$ \\
\hline $\mathrm{T}$ & $2.20 \pm 0.04$ & $2.78 \pm 0.04$ & $3.46 \pm 0.06$ \\
\hline $\mathrm{U}$ & $2.41 \pm 0.04$ & $2.62 \pm 0.05$ & $3.42 \pm 0.06$ \\
\hline V & $2.32 \pm 0.05$ & $2.67 \pm 0.05$ & $3.40 \pm 0.06$ \\
\hline W & $1.35 \pm 0.08$ & $1.42 \pm 0.08$ & $2.14 \pm 0.09$ \\
\hline Total & $2.69 \pm 0.05$ & $3.10 \pm 0.06$ & $3.84 \pm 0.07$ \\
\hline
\end{tabular}

The experimental conditions were $[\text { substrate }]_{\mathrm{T}}=100 \mathrm{ppm}$, [iodine $]_{\mathrm{T}}=20 \mathrm{ppm}, \mathrm{pH}=4$, and temperature at $37^{\circ} \mathrm{C}$. The values obtained from $t$-test were: $t_{44}=2.92(n=46)$. The critical value $\left(t_{44}\right)$ was 2.02. a) Rest; $\alpha$-amylase activity of saliva that was in term of rest time ( 30 min before exercise), $b$ ) Pre-exercise; $\alpha$-amylase activity of saliva that was just before exercise and (c) Post-exercise; $\alpha$-amylase activity of a saliva after $2 \mathrm{~h}$ exercise. 
tected concentration level were corresponded.

Comparison with Other Analytical Methods Previous reported method $^{13)}$ requires dilution of samples, whereas the presented method can directly measure samples $(0.25-5.0 \mathrm{KNU} / \mathrm{mL})$. In addition, the method requires small volume of a sample $(20 \mu \mathrm{L})$, and 30 samples was sequential measured within one hour. Otherwise, an ELISA with spectrophotometry $^{9)}$ simultaneously measured 96 samples using microplate. However the method was also required dilution of samples. The sample dilution is very inconvenient in sequential analysis. The present method has advantages in detection limits as compared with the chemical sensor (saliva amylase monitor). ${ }^{10,11)}$ Measurement values $(n=5)$ obtained by the presented method were cross-checked by the published method. ${ }^{13)}$ The data obtained by both methods were identical at the $95 \%$ confidence level $\left(n=16,|t|=0.02\right.$, critical $t_{n-1}=2.12$ $(p=0.05))$.

In conclusion, the enzyme degradation reaction in flow tubing was achieved by finding the spectrophotometric properties of iodine-starch complexes and optimizing the enzyme reaction in the flow system. To exhibit the methodological possibility for the stress diagnostics, salivary amylase as an indicator of body stress was determined in the situation before and after exercise. The tendency of the data measured in this study corresponded with previous reports.

Supplemental Information Additional information as noted in the text. This material is available free in Biological and Pharmaceutical Bulletin web.

\section{REFERENCES}

1) Vining RF, McGinley RA, Maksvytis JJ, Ho KY. Salivary cortisol: a better measure of adrenal cortical function than serum cortisol. Ann. Clin. Biochem., 20, 329-335 (1983).

2) Kirschbaum C, Hellhammer DH. Salivary cortisol in psychobiological research: an overview. Neuropsychobiology, 22, 150-169 (1989).

3) Simon JP, Bader MF, Aunis D. Secretion from chromaffin cells is controlled by chromogranin A-derived peptides. Proc. Natl. Acad. Sci. U.S.A., 85, 1712-1716 (1988).

4) Nakane H, Asami O, Yamada Y, Ohira H. Effect of negative air ions on computer operation, anxiety and salivary chromogranin Alike immunoreactivity. Int. J. Psychophysiol., 46, 85-89 (2002).

5) Yamaguchi M, Kanemori T, Kanemaru M, Mizuno Y, Yoshida H. Correlation of stress and salivary amylase activity. Jpn. J. Med. Electron. Biol. Eng., 39, 234-239 (2001).

6) Takai N, Yamaguchi M, Aragaki T, Eto K, Uchihashi K, Nishikawa Y. Effect of psychological stress on the salivary cortisol and amylase levels in healthy young adults. Arch. Oral Biol., 49, 963-968 (2004).

7) Walsh NP, Blannin AK, Clark AM, Cook L, Robson PJ, Gleeson M. The effects of high-intensity intermittent exercise on saliva IgA, total protein and alpha-amylase. J. Sports Sci., 17, 129-134 (1999).

8) Skosnik PD, Chatterton RT Jr, Swisher T, Park S. Modulation of attentional inhibition by norepinephrine and cortisol after psychological stress. Int. J. Psychophysiol., 36, 59-68 (2000).

9) Rohleder N, Nater UM, Wolf JM, Ehlert U, Kirschbaum C. Psychosocial stress-induced activation of salivary alpha-amylase: an indicator of sympathetic activity? Ann. N. Y. Acad. Sci., 1032, 258-263 (2004).

10) Yamaguchi M, Kanemori T, Kanemaru M, Takai N, Mizuno Y, Yoshida H. Performance evaluation of salivary amylase activity monitor. Biosens. Bioelectron., 20, 491-497 (2004).

11) Yamaguchi M, Deguchi M, Wakasugi J, Ono S, Takai N, Higashi T, Mizuno Y. Hand-held monitor of sympathetic nervous system using salivary amylase activity and its validation by driver fatigue assessment. Biosens. Bioelectron., 21, 1007-1014 (2006).

12) van Staden JF, Mulaudzi LV. Flow injection spectrophotometric assay of $\alpha$-amylase activity. Anal. Chim. Acta, 421, 19-25 (2000).

13) Hansen PW. Determination of fungal $\alpha$-amylase by flow injection analysis. Anal. Chim. Acta, 158, 375-377 (1984).

14) Carlsen M, Marcher J, Nielsen J. An improved FIA-system for measuring $\alpha$-amylase in cultivation media. Biotechnol. Tech., 8 , 479-482 (1994).

15) Zhang Z, Seitz WR, O'Connell K. Amylase substrate based on fluorescence energy transfer. Anal. Chim. Acta, 236, 251-256 (1990).

16) Sakač N, Sak-Bosnar M, Horvat M, Madunic-Cacic D, Szechenyi A, Kovacs B. A new potentiometric sensor for the determination of $\alpha$-amylase activity. Talanta, 83, 1606-1612 (2011).

17) Pimstone NR. A study of the starch iodine complex: A modified colorimetric microdetermination of amylase in biologic fluids. Clin. Chem., 10, 891-906 (1964).

18) Nakano T, Suzuki T. Utility of including amylase activity values for saliva as the index of physical condition of the athlete. Nagoya Gakuin University Review, Humanities, Natural Sciences, 46, 45-54 (2009). 